\title{
Using hepatitis C prevalence to estimate HIV epidemic potential among people who inject drugs in the Middle East and North Africa
}

\author{
Ghina R. Mumtaz ${ }^{\mathrm{a}, \mathrm{b}}$, Helen A. Weiss ${ }^{\mathrm{b}}$, Peter Vickerman ${ }^{\mathrm{c}}$, \\ Natasha Larke ${ }^{b}$ and Laith J. Abu-Raddad ${ }^{a, d, e}$
}

\begin{abstract}
Objectives: The objective of this study is to understand the association between HIV and hepatitis $\mathrm{C}$ virus (HCV) among people who inject drugs (PWIDs) in the Middle East and North Africa (MENA), and to estimate HIV epidemic potential among PWIDs using HCV prevalence.

Design/methods: Using data from a systematic review of HIV and HCV among PWID in MENA, we conducted two analyses, stratified by HIV epidemic state: a meta-analysis of the risk ratio of $\mathrm{HCV}$ to HIV prevalence $\left(\mathrm{RR}_{\mathrm{HCV} / \mathrm{HIV}}\right)$ using DerSimonian-Laird random-effects models, and multivariable linear regression predicting log HIV prevalence. The HCV-HIV association from both analyses was used to estimate HIV prevalence at endemic equilibrium. We compared predicted with current HIV prevalence to classify HIV epidemic potential at country-level as low, medium or high, using predefined criteria.

Results: The review identified $88 \mathrm{HCV}$ prevalence measures among PWID in MENA, of which 54 had a paired HIV prevalence measure. The pooled $R_{\text {HCV/HIV }}$ were 16,4 and 3 in low-level, emerging and established HIV epidemics, respectively. There was a significant linear relationship between HCV and HIV at endemic equilibrium $(P=0.002)$. The predicted endemic HIV prevalence ranged between $8 \%$ (Tunisia) and $22 \%$ (Pakistan). Of the nine countries with data, five have high and three medium HIV epidemic potential. Only one country, Pakistan, appears to have reached saturation.

Conclusion: HCV prevalence could be a predictor of future endemic HIV prevalence. In MENA, we predict that there will be further HIV epidemic growth among PWID. The proposed methodology can identify PWID populations that should be prioritized for HIV prevention interventions. Copyright ๑ 2015 Wolters Kluwer Health, Inc. All rights reserved.
\end{abstract}

AIDS 2015, 29:1701-1710

Keywords: epidemic, hepatitis C virus, HIV, Middle East and North Africa, people who inject drugs, prediction

\section{Introduction}

People who inject drugs (PWID) are a key population at risk for HIV infection in the Middle East and North
Africa (MENA) [1]. A recent systematic review documented emerging HIV epidemics among PWID in at least one-third of MENA countries [2]. Most epidemics are recent and suggest potential for further

\footnotetext{
anfectious Disease Epidemiology Group, Weill Cornell Medical College - Qatar, Cornell University, Qatar Foundation Education City, Doha, Qatar, ${ }^{\mathrm{b}} \mathrm{MRC}$ Tropical Epidemiology Group, Department of Infectious Disease Epidemiology, Faculty of Epidemiology and Population Health, London School of Hygiene and Tropical Medicine, London, ${ }^{\mathrm{c} S}$ School of Social and Community Medicine, University of Bristol, Bristol, UK, ${ }^{\mathrm{d} D e p a r t m e n t ~ o f ~ H e a l t h c a r e ~ P o l i c y ~ a n d ~ R e s e a r c h, ~ W e i l l ~ C o r n e l l ~ M e d i c a l ~}$ College, Cornell University, Ithaca, New York, and ${ }^{\mathrm{e}}$ Vaccine and Infectious Disease Institute, Fred Hutchinson Cancer Research Center, Seattle, Washington, USA.

Correspondence to Ghina R. Mumtaz, Weill Cornell Medical College - Qatar, Qatar Foundation - Education City, P.O. Box 24144, Doha, Qatar.

Tel: +974 4492 8406; fax: +974 4492 8422; e-mail: gim2006@qatar-med.cornell.edu Received: 17 December 2014; revised: 26 May 2015; accepted: 28 May 2015.
} 
growth [2]. Our research question is to estimate the HIV epidemic potential among PWID, that is to estimate the predicted growth in HIV prevalence to the time it reaches endemic equilibrium, in order to inform policy and intervention programmes.

Although HIV and, in rare instances [3], hepatitis C virus (HCV) can be transmitted sexually, sharing of needles/ syringes is their main transmission mode among PWID [4]. HCV is about 10 times more infectious than HIV through percutaneous exposure [5-7], partially explaining why HCV is hyperendemic among PWID globally, but HIV is not $[8,9]$. As HCV is transmitted more rapidly than HIV along the same transmission route, it could be used as a marker of HIV potential spread among PWID. Ecological studies and mathematical modelling have found a positive association between HCV and HIV among PWID globally, with a threshold HCV prevalence of about $30 \%$ to sustain HIV transmission $[6,7,10]$. The relationship between the two infections is however complex, dependent on the setting and risk environment, and overall remains poorly understood [7].

The use of HCV as a population-level marker of injecting risk behaviour and, consequently, HIV risk and epidemic potential is appealing with the constrained resources for HIV research and programming. In MENA, wherein surveillance is rather limited and difficult to implement, using existing data to make inferences about future size of HIV epidemics is a potentially efficient strategy.

The aims of this study are to understand analytically the epidemiological links and association between HCV and HIV infections among PWID, and to estimate HIV epidemic potential in this population across MENA countries, using data compiled through the systematic review of HIV and HCV among PWID in MENA [2].

\section{Materials and methods}

\section{Conceptual framework and hypotheses}

We hypothesize that endemic HCV prevalence predicts HIV prevalence among PWID, as both infections result from injecting risk behaviour. We further hypothesize that the relationship between HCV and HIV prevalence is dependent on the HIV epidemic state among PWID, whether low-level (HIV has not reached significant levels), emerging (HIV prevalence has started its initial growth and is increasing) or established/saturated (the epidemic has reached its peak and HIV prevalence is approaching, or already is at, its endemic level) [2]. We hypothesize that the association between HCV and HIV in established HIV epidemics can be used to predict HIV epidemic potential among PWID in other settings, even where the HIV epidemic is still at low level or emerging.
Our hypothesis is motivated by theoretical mathematical modelling work on the joint epidemiology of HCV and HIV. A stochastic compartmental model was built to simulate HCV and HIV epidemic trajectories among a prototype PWID population (V. Akbarzadeh, G.R. Mumtaz, L.J. Abu-Raddad, in preparation). Figure 1a depicts a case scenario wherein HIV is introduced into a PWID population originally naive to HIV and where $\mathrm{HCV}$ is endemic at high prevalence indicating substantial injecting risk behaviour. When the HIV epidemic is still at low level, HCV prevalence is not predictive of the level of HIV prevalence (Fig. 1a). When the HIV epidemic emerges, HCV prevalence becomes associated with HIV prevalence; however, the magnitude of this association varies with time, as HIV prevalence is still increasing (Fig. 1a). It is only when the HIV epidemic becomes established, that the association between HCV and HIV prevalence becomes stable and simply quantified, as both infections have reached endemicity (Fig. 1a). This pattern is reflected in the risk ratio of HCV to HIV prevalence ( $\left.\mathrm{RR}_{\mathrm{HCV} / \mathrm{HIV}}\right)$ (Fig. 1b). As the HIV epidemic emerges, the $\mathrm{RR}_{\mathrm{HCV} / \mathrm{HIV}}$ decreases until it reaches a plateau, with a stable $\mathrm{RR}_{\mathrm{HCV} / \mathrm{HIV}}$, when the HIV epidemic reaches equilibrium (established HIV epidemic, Fig. 1b). Endemic HCV prevalence can accordingly be used to predict the future size (at endemic equilibrium) of the HIV epidemic among PWID. Varying levels of endemic $\mathrm{HCV}$ prevalence entail varying levels of endemic HIV prevalence.

On the basis of the above analytical framework, we will stratify our analyses by HIV epidemic state to explore the differential association between HCV and HIV in the three epidemic states. Results of the analyses in settings of established HIV epidemics will be used to predict HIV epidemic potential among PWID.

\section{Sources of data}

This study used data extracted from a recent systematic review whose main objective was to assess the status of the HIV epidemic among PWID in 23 MENA countries that are part of the MENA definition of the Joint United Nations Programme on HIV/AIDS (UNAIDS), WHO and World Bank [2]. In brief, the review followed PRISMA guidelines and included all studies on PWID, published in PubMed, Embase and regional databases, and unpublished in the form of country reports, until 16 December 2013 [2].

In the present study, we started with $197 \mathrm{HIV}$ and 93 HCV prevalence measures among PWID (Fig. 2) [2]. After excluding four HIV and five HCV self-reported prevalence measures, there were 71 paired biological HCV-HIV data points, that is HCV and HIV prevalence on the same PWID population. As we are studying the relationship between the two infections, the analysis was restricted to settings wherein HIV has already been introduced, and thus, $16 \mathrm{HCV}-\mathrm{HIV}$ data points with zero 
(a)

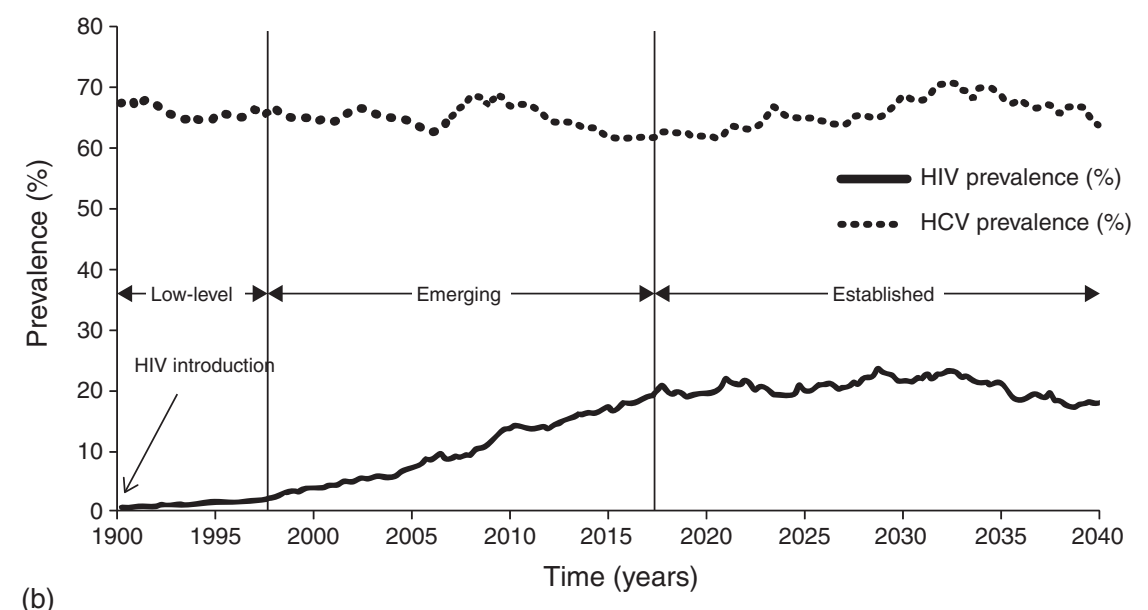

(b)

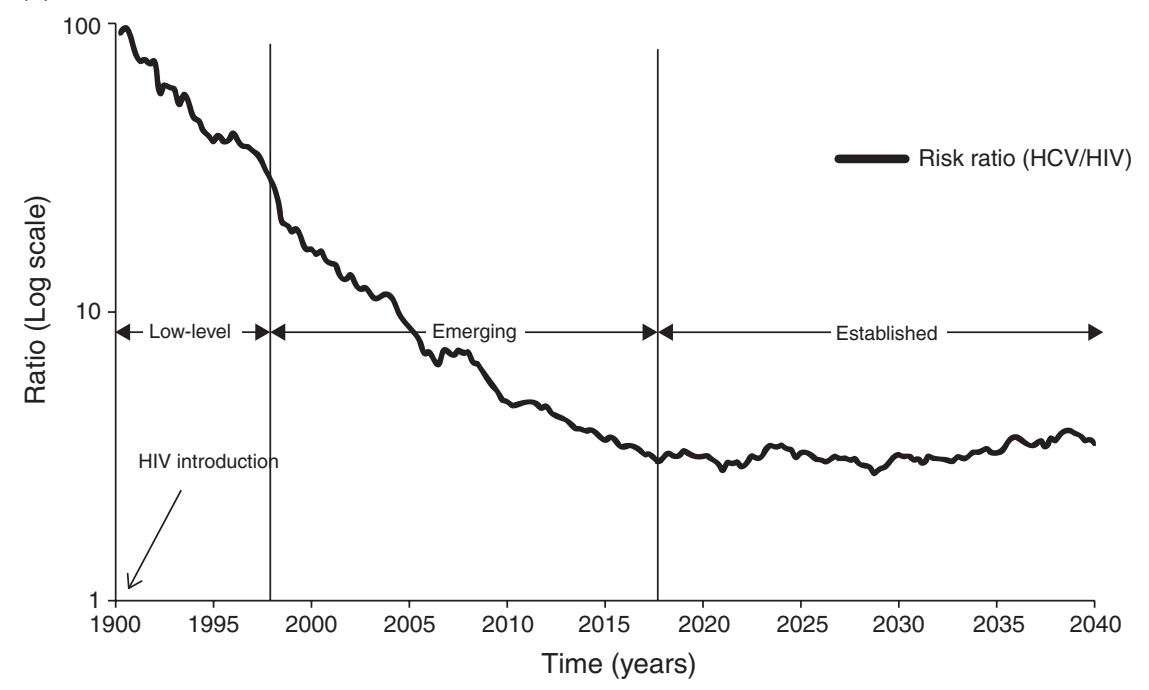

Fig. 1. Mathematical modelling simulation of an HIV epidemic expansion among a prototype PWID population. (a) A case scenario for an HIV epidemic expansion in a PWID population wherein HCV is endemic at a prevalence level of about $75 \%$ indicating high injecting risk behaviour. HIV is introduced in 1990, starts emerging with increasing prevalence about two decades later in the late 1990s, and saturates near the year 2020 at a prevalence of about 20\%. The corresponding three HIV epidemic states - low level, emerging and established - are shown on the graph. (b) The risk ratio of HCV to HIV prevalence (RR $\left.\mathrm{HCV}_{\text {HIV }}\right)$ among this PWID population.

HIV prevalence were excluded. One outlier $(89 \%$ HIV prevalence in Libya [11]) was further excluded, leaving 54 paired HCV-HIV prevalence measures in the statistical analysis (Fig. 2).

\section{Classification by HIV epidemic state}

Country-specific criteria were devised to classify the data into one of three HIV epidemic states: low-level, emerging or established [2]. This classification was a main aim of the MENA PWID systematic review, wherein a comprehensive analysis of available HIV biological data was performed using rigorous methodology to characterize HIV epidemic state at country-level [2]. HCV biological data were not part of the criteria to characterize HIV epidemic states. Details of the methods, classification criteria and findings that led to these epidemic states can be found in the corresponding publication [2]. The epidemic states for countries in the present study are summarized in Table S1. This baseline classification was adjusted in specific cases to accommodate for geographic heterogeneity in HIV epidemic dynamics within a single country [2]. For example, in Iran, all data points after 2006 were classified as 'established', except for one province, Isfahan, where HIV prevalence among PWID has been consistently negligible [2].

\section{Data analysis}

Analyses were performed in STATA/SE 13.0 (Stata Corp., College Station, Texas, USA). Two types of analyses were conducted to understand the association between the two infections: a meta-analysis of the 


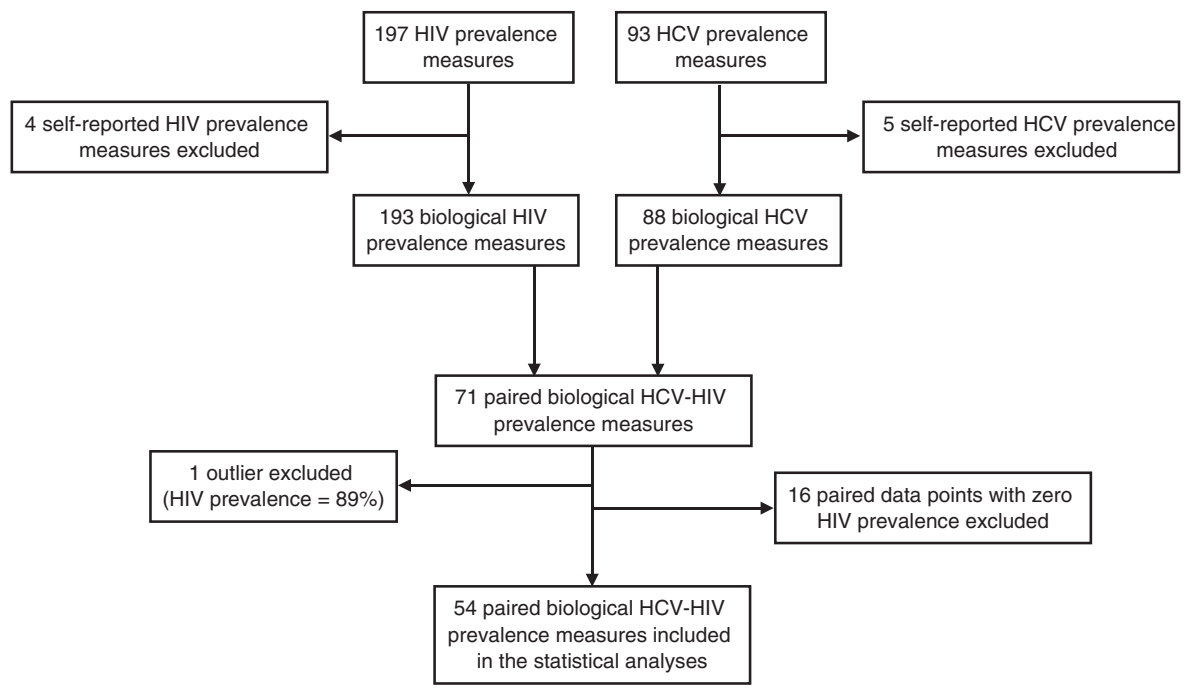

Fig. 2. Sample selection process.

$\mathrm{RR}_{\mathrm{HCV} / \mathrm{HIV}}$ and linear regression to quantify the extent to which any change in HIV prevalence is related to change in HCV prevalence. Results of these analyses were used to predict future HIV prevalence at endemic equilibrium among PWID at country-level.

\section{Meta-analysis}

Three meta-analyses of the $R_{\text {HCV/HIV }}$ in each of the three HIV epidemic states were applied. The $\mathrm{RR}_{\mathrm{HCV} / \mathrm{HIV}}$ is an 'ecological' risk ratio defined as the ratio of the prevalence ('risk') of HCV to that of HIV in the same population. The objective of using this measure was to quantify the association between the two infections at the population level.

The $54 \mathrm{RR}_{\mathrm{HCV} / \mathrm{HIV}}$ were pooled using DerSimonianLaird random-effects models with inverse variance weighting using the metan command [12]. The $I^{2}$ statistic was calculated as a measure of heterogeneity in effect size, which is the proportion of overall between-study variation in $\mathrm{RR}_{\mathrm{HCV} / \mathrm{HIV}}$ that is due to differences between studies in effect size and not chance [12].

\section{Linear regression}

Three multivariable linear regression models, one in each HIV epidemic state, were fitted to the data. Log HIV prevalence was the dependent variable. Explanatory variables included $\mathrm{HCV}$ - our main predictor of interest - country and study characteristics including sampling technique (probability versus nonprobability-based), sample size $(<100$ or $\geq 100)$ and study site (community, facility-based or prison). The regression analyses used robust standard errors to adjust for heteroscedasticity. Each data point was weighed by its sample size. As a first step, all explanatory variables were included in the model and only variables significant at $P$ value less than 0.1 (in addition to $\mathrm{HCV}$ ) were kept in the final model.

\section{HIV epidemic potential prediction}

The final regression model predicting HIV prevalence in settings of established HIV epidemics was used to estimate the prevalence and 95\% confidence intervals of HIV at endemic equilibrium among PWID, using the margins command. On the basis of predictions of the fitted model, margins calculate HIV prevalence for specific values of covariates in the model. The predictions were made using the mean HCV prevalence among PWID per country using all available biological HCV prevalence measures (including where HIV is zero) [11,13-78]. The prevalence of HIV at endemic equilibrium was also estimated using results of the meta-analysis by dividing the mean HCV prevalence by the pooled $\mathrm{R}_{\mathrm{HCV} / \mathrm{HIV}}$. Results of the two methods of prediction were compared.

We devised criteria to classify HIV epidemic potential. They depend on comparing the predicted HIV prevalence with the most recent representative HIV prevalence as extracted from surveillance studies [2]. HIV epidemic potential was classified as high, moderate or low. High epidemic potential was considered if the estimated HIV prevalence at endemic equilibrium was at least 10 absolute percentage points higher than current HIV prevalence and at least twice as high as current HIV prevalence (estimated/ current HIV prevalence $>2$ ). Low epidemic potential was considered if the estimated HIV prevalence at endemic equilibrium was less than five absolute percentage points higher than current HIV prevalence and less than $20 \%$ higher than current HIV prevalence (estimated/current HIV prevalence $<1.2$ ). Moderate epidemic potential was considered in remaining scenarios.

\section{Results}

The 54 paired HCV-HIV prevalence measures among PWID were from five countries: Iran $(n=31)$, Afghani$\operatorname{stan}(n=11)$, Pakistan $(n=8)$, Morocco $(n=2)$ and 
Tunisia $(n=2)$. There were 20 paired HCV-HIV measures in low-level, 22 in emerging, and 12 in established HIV epidemic settings. Iran was the only country in the established epidemic strata. The data are summarized in Table S2.

The meta-analyses showed that the $\mathrm{RR}_{\mathrm{HCV} / \mathrm{HIV}}$ is highest in low-level HIV epidemics at 16.3 [95\% confidence interval (95\% CI) 11.5-23.1], followed by that in emerging HIV epidemics at 3.8 (95\% CI 3.1-4.7), while the lowest $\mathrm{RR}_{\mathrm{HCV} / \mathrm{HIV}}$ was observed in established HIV epidemics at 2.8 (95\% CI 2.1-3.6) (Table 1). The corresponding forest plots are in Figures S1-S3. These results suggest that HIV prevalence at endemic equilibrium is about one-third of the endemic HCV prevalence, assuming no major confounding effect by other predictors. There was evidence of heterogeneity between studies in the three epidemic states with an $I^{2}$ of $80-87 \%(P<0.001)$, indicating that the variation in $\mathrm{RR}_{\mathrm{HCV} / \mathrm{HIV}}$ between studies is due to differences in effect size, and not chance.

Table 2 summarizes the final multivariable regression models predicting log HIV prevalence. HCV prevalence was not associated with HIV in low-level HIV epidemics $(\beta=-1.3,95 \% \mathrm{CI}-3.4$ to 0.9$)$. In these settings, country and study site were the significant predictors of HIV. HCV was a significant predictor of HIV prevalence in sites wherein the HIV epidemic is emerging or established. In emerging epidemics, HCV was significantly associated with the highest increase in log HIV prevalence compared with the other epidemic states $(B=5.4,95 \%$ CI $2.7-8.2)$. Country and study site were also significant predictors of HIV in emerging epidemic states. In established epidemics, HCV prevalence was the only predictor of $\mathrm{HIV}(B=1.7,95 \%$ CI $0.8-2.7)$ (Table 2$)$.

Table 3 displays the predicted HIV prevalence at endemic equilibrium among PWID in MENA using results of both regression analysis and meta-analysis. The two methods predicted similar endemic HIV prevalence, with a median difference of $10 \%$ between the two methods. The median estimated HIV prevalence across countries was 17\% [interquartile range (IQR): 13-20\%] and 19\% (IQR: $13-22 \%$ ) as predicted by the regression and metaanalysis models, respectively. The highest estimated endemic HIV prevalence was $20-22 \%$ in Egypt,
Morocco, Pakistan, Saudi Arabia and Syria. The lowest was $8 \%$ in Tunisia (Table 3).

HIV epidemic potential was found to be high among PWID in Egypt, Lebanon, Palestine, Saudi Arabia and Syria, and moderate in Afghanistan, Morocco and Tunisia. Apart from Iran that was used to derive the predictive relationship, Pakistan was the only country with low epidemic potential and where the HIV epidemic among PWID is predicted to have reached or is close to saturation (Table 3).

\section{Discussion}

This study illustrates our hypothesis that HCV prevalence can be used to predict HIV epidemic potential among PWID. With HCV being hyperendemic among PWID globally, its prevalence is indicative of the level of injecting risk behaviour and therefore could possibly predict future HIV prevalence. Our analyses in MENA suggest that HIV prevalence will reach, at endemic equilibrium, about one-third of HCV prevalence in a given PWID population wherein HIV is introduced.

The association between HCV and HIV among PWID is complex and varied depending on HIV epidemic state, as postulated in our hypothesis and motivated by the modelling simulations. When the HIV epidemic was at low level, HCV was not predictive of HIV prevalence. HIV may have been recently introduced, or may have been spreading for some time but slowly and inefficiently due to stochastic effects. In these settings, HIV prevalence is not a reflection of the level of injecting risk behaviour. In an emerging HIV epidemic, the intensity of HIV prevalence growth depends on the level of injecting risk behaviour, and this is confirmed by the observed association between HCV and HIV prevalence. However, there are also other predictors of epidemic expansion intensity including time since epidemic emergence, and other factors such as setting of injection and country, both of which were significant predictive proxies for the risk environment (Table 2). In established HIV epidemics, and confirming our hypothesis (Fig. 2), HCV was the only significant predictor of HIV prevalence. This highlights how HCV is a proxy of injecting risk behaviour in PWID

Table 1. Pooled risk ratio of hepatitis $C$ virus to $H I V$ prevalence $\left(R_{\mathrm{HCV} / \mathrm{HIV}}\right)$ among people who inject drug in Middle East and North Africa.

\begin{tabular}{|c|c|c|c|c|c|c|c|}
\hline \multirow[b]{2}{*}{ Epidemic state } & \multirow[b]{2}{*}{ No datasets } & \multirow{2}{*}{$\begin{array}{l}\text { Total un-weighted } \\
\text { HCV prevalence }\end{array}$} & \multirow{2}{*}{$\begin{array}{l}\text { Total un-weighted } \\
\text { HIV prevalence }\end{array}$} & \multirow{2}{*}{$\begin{array}{c}\text { Studies } R_{\text {HCV/HIV }} \\
\text { Median (IQR) }\end{array}$} & \multicolumn{3}{|c|}{ Pooled RR $\mathrm{HCV}_{\mathrm{HIIV}}$} \\
\hline & & & & & $\%(95 \% \mathrm{Cl})$ & $P^{2}$ & $P$ \\
\hline Low level & 20 & $3264 / 7699(42.4 \%)$ & $217 / 7730(2.8 \%)$ & $13.8(9.6-56.9)$ & $16.3(11.5-23.1)$ & $80.2 \%$ & 0.000 \\
\hline Emerging & 22 & $2200 / 3749(58.7 \%)$ & $554 / 3698(15.0 \%)$ & $4.4(3.1-5.6)$ & $3.8(3.1-4.7)$ & $79.5 \%$ & 0.000 \\
\hline Established & 12 & $1635 / 3498(51.1 \%)$ & $605 / 3508(23.2 \%)$ & $3.3(2.1-4.2)$ & $2.8(2.1-3.6)$ & $87.2 \%$ & 0.000 \\
\hline
\end{tabular}

$\mathrm{Cl}$, confidence interval; $\mathrm{HCV}$, hepatitis $\mathrm{C}$ virus; $\mathrm{IQR}$, interquartile range. 
Table 2. Multivariable linear regression models ${ }^{a}$ predicting log of HIV among people who inject drug in Middle East and North Africa, stratified by HIV epidemic state among people who inject drug.

\begin{tabular}{|c|c|c|c|c|c|}
\hline HIV epidemic state & Variables & $\beta$ & $95 \% \mathrm{Cl}$ & $P$ & $R^{2}$ \\
\hline \multirow[t]{12}{*}{ Low level $(n=16)$} & HCV prevalence ${ }^{b}$ & -1.3 & -3.4 to 0.9 & 0.216 & 0.754 \\
\hline & Country & & & 0.000 & \\
\hline & Afghanistan & ref & & & \\
\hline & Iran & -0.3 & -1.6 to 1.0 & & \\
\hline & Morocco & -1.8 & -3 to -0.6 & & \\
\hline & Pakistan & -0.6 & -2.4 to 1.1 & & \\
\hline & Tunisia & 0.3 & -1.0 to 1.6 & & \\
\hline & Study site & & & 0.025 & \\
\hline & Community & ref & & & \\
\hline & Prison & 1.3 & -0.3 to 3.0 & & \\
\hline & Facility-based & -0.1 & -1.7 to 1.5 & & \\
\hline & Mixed & 0.4 & -1.3 to 2.1 & & \\
\hline \multirow{11}{*}{ Emerging $(n=21)$} & HCV prevalence ${ }^{b}$ & 5.4 & $2.7-8.2$ & 0.001 & 0.724 \\
\hline & Country & & & 0.001 & \\
\hline & Afghanistan & ref & & & \\
\hline & Iran & -2.2 & -3.1 to -1.4 & & \\
\hline & Morocco & -0.6 & -1.1 to -0.2 & & \\
\hline & Pakistan & -1.3 & -2.2 to -0.3 & & \\
\hline & Study site & & & 0.000 & \\
\hline & Community & ref & & & \\
\hline & Prison & 1.0 & $0.1-2.0$ & & \\
\hline & Facility-based & 2.8 & $1.3-4.2$ & & \\
\hline & Mixed & 2.8 & $2.0-3.7$ & & \\
\hline Established $(n=12)$ & HCV prevalence ${ }^{b}$ & 1.7 & $0.8-2.7$ & 0.002 & 0.340 \\
\hline
\end{tabular}

$\mathrm{Cl}$, confidence interval.

a Weighting for sample size and using robust methods to adjust for heteroscedasticity. The displayed final models include only statistically significant covariates.

${ }^{\mathrm{b}}$ Proportion.

and can be used to generate inferences on the size of HIV epidemics, regardless of current HIV epidemic state. HCV prevalence 'summarizes' collectively the risk environment and acts as a 'temperature scale' of the level of risk behaviour and HIV epidemic potential in a PWID population.

We estimated HIV epidemic potential in nine countries where $\mathrm{HCV}$ prevalence data were available. Both the regression analysis and meta-analysis produced similar results, not a surprising outcome, as HCV was the only significant predictor of HIV in the regression analysis of established HIV epidemics. In most countries, we found room for further HIV growth, with five of these having high and three moderate HIV epidemic potential, highlighting the emerging and growing nature of the HIV epidemic among PWID in MENA, as suggested recently [1,2]. Although HIV prevalence in Pakistan showed an increasing trend from $10.8 \%$ in 2005 to $25.2 \%$ in 2011 [79-82], our predictions suggest that the HIV epidemic could be reaching saturation with limited potential for further growth. Still, HIV incidence remains considerable in such settings of high HIV prevalence, and the limited epidemic potential should not be interpreted as low priority for prevention interventions.

Our findings have important policy implications, as they provide a simple tool to identify PWID populations at a high risk of future HIV epidemic expansion. In half of MENA countries with considerable epidemic potential, the HIV epidemic is still at low level, and therefore, there is significant benefit in preventing the infection from taking root in this population. In countries where epidemic status is unknown, using HCV prevalence data could help identify hidden HIV epidemics before they grow substantially. One example is Saudi Arabia where the high HCV prevalence suggests the potential for substantial, though undetected, HIV transmission. Recent case notification data also hint at this conclusion [1]. Although the top priority for public health programmes should be settings already at known high HIV incidence, such country-specific predictions highlight the need to also implement intervention packages and conduct surveillance studies in settings with high HIV epidemic potential and where there could be complacency in view of the current low HIV prevalence.

There were several limitations in our study. The analysis used a relatively simple approach to a probably complex association. We assumed a linear association between HCV and HIV, which fitted well our data. However, the effect size can be affected by heterogeneity in risk and nonlinearity in this association, as suggested by the observed high $I^{2}$ values, earlier modelling work $[7,10]$ and an ecological analysis [6]. The latter also suggests a threshold effect where HIV prevalence would remain negligible in countries with low HCV prevalence [6], such as Tunisia. The HCV-HIV association can also be affected by interventions, if they affect each infection differentially, such as antiretroviral therapy (ART) that 


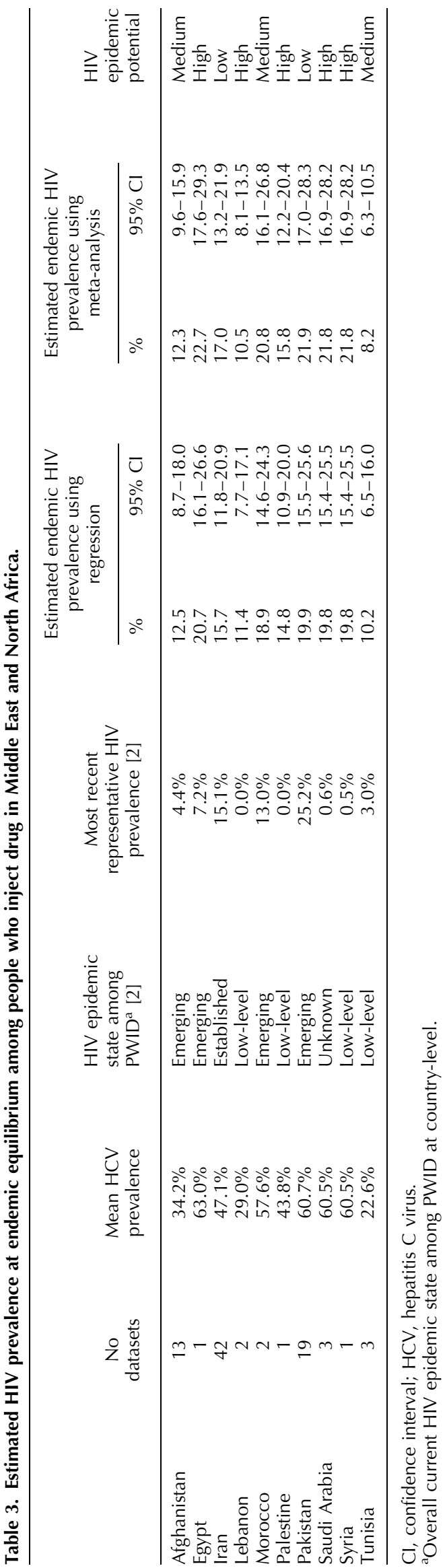

affects survival with HIV and infection transmission. In MENA, ART coverage is low across countries, with a median of 16\% (IQR: 6-17\%) [83]. If ART coverage increases substantially in the coming years, our current predictions may underestimate endemic HIV prevalence with the longer survival effect. ART can affect the quantitative HCV-HIV association, but not its existence nor the principle behind it. When applied to settings with substantial ART coverage, a more generic association could be derived by including ART coverage as one additional covariate in the regression models.

We assumed that HCV and HIV among PWID are transmitted through sharing of needles/syringes and that there is limited sexual transmission of these infections in this population. We also assumed a negligible effect of background HCV prevalence due to iatrogenic transmission, as HCV prevalence in the population at large is generally much smaller than $\mathrm{HCV}$ prevalence among PWID $[2,84,85]$. We further assumed that HCV is at endemic equilibrium. All of these assumptions are only approximately valid.

The small sample size of paired HCV-HIV measures limited the range of mathematical complexity that could be explored and number of potential confounders to control for and prevented us from conducting metaregressions to account for heterogeneity in effect size. Iran was also the only country providing data in the established HIV epidemic state, but this could introduce bias if the data from other countries are not representative of the same generic HCV-HIV epidemiological association. The predictions of HIV epidemic potential also depend on the quality of HCV prevalence data. For some countries, there were few measures and these may not be representative of the PWID population at large. Our predictions were also made at the national level, but there could be geographic heterogeneity in risk environment, leading to geographically clustered HCV prevalence and predicted HIV epidemic size. For example in Pakistan, HCV prevalence of over 90\% was observed in Karachi and Lahore [2], while the mean prevalence at the country-level was only $61 \%$. Finally, our methodology provides only the scale and not the timeframe of predicted epidemic growth. It is expected, however, based on generic mathematical modelling results $[11,86]$, that the pace of an epidemic should correlate with its HIV epidemic potential, as estimated here.

Despite these limitations, our study provides important insights into a poorly understood and barely investigated association [6,7]. Using a mechanistic and analytical methodology, our study confirms that the HCV-HIV association is robust and characterized differentially by HIV epidemic state. The association can also be described, at least grossly, using a simple methodology that can be easily and widely applied to assess HIV epidemic potential. Even if some of the input data used to generate the 
predictions may prove unrepresentative with further empirical data, the value of this work remains in delineating a powerful concept of using data on one infection, HCV, to estimate the scale of epidemics of another infection, HIV. This concept exploits the epidemiological links that underpin the dynamics of two infections sharing the same mode of transmission and propagating on the same network structure. With further data over the coming years, and use of global data on PWID beyond MENA, the value of this approach can be enhanced for a wider applicability across countries and contexts, including fine-grained predictions at small geographic scales. Moreover, if combined with appropriate dynamic mathematical modelling, our results could be used to generate predictions for the time evolution of epidemics.

In conclusion, we described a concept that has a pragmatic and useful application, to predict future HIV epidemics and their scales using $\mathrm{HCV}$ prevalence. The proof of concept was manifested by modelling the HCVHIV association in few countries, and then generating predictions for more countries with limited HIV data. In addition to informing our theoretical understanding of the overlapping epidemiology of these two infections, this approach optimizes the use of available data and informs resources allocation and planning of interventions and research studies. Findings from this proposed methodology can complement those of other methods of measurement and estimation such as prospective incidence studies, and indirect estimations of HIV incidence using the innovative HIV incidence assays and mathematical models $[87,88]$. Triangulation of complimentary approaches will allow the corroboration of findings across different methods, the adjustment of potential limitations in each one of them and is essential for the formulation of an optimal HIV response.

\section{Acknowledgements}

G.R.M. designed the study, conducted the analyses and wrote the first draft of the manuscript. H.A.W. coled the study design, study conduct and analyses. P.V. and N.L. contributed to the development of the study methodology. L.J.A. conceived the study and co-led the study design, study conduct and analyses. All authors contributed to the interpretation of findings and drafting of the manuscript. All authors approved the final version of the manuscript.

This publication was made possible by NPRP grant number (NPRP 04-924-3-251) from the Qatar National Research Fund (a member of Qatar Foundation). Additional support was provided by the Biostatistics, Epidemiology and Biomathematics Research Core at the Weill Cornell Medical College in Qatar. The statements made herein are solely the responsibility of the authors and the funders had no role in study design, data collection and analysis, decision to publish or preparation of the manuscript.

\section{Conflicts of interest}

There are no conflicts of interest.

\section{References}

1. Mumtaz GR, Riedner G, Abu-Raddad LJ. The emerging face of the HIV epidemic in the Middle East and North Africa. Curr Opin HIV AIDS 2014; 9:183-191.

2. Mumtaz GR, Weiss HA, Thomas SL, Riome S, Setayesh $H_{\text {, }}$ Riedner G, et al. HIV among people who inject drugs in the Middle East and North Africa: systematic review and data synthesis. PLoS Med 2014; 11:e1001663.

3. Gorgos L. Sexual transmission of viral hepatitis. Infect Dis Clin North Am 2013; 27:811-836.

4. Nelson K, Williams C. Infectious disease epidemiology: theory and practice. 2nd ed. Boston, MA: Jones and Barlett Publishers; 2007.

5. Cainelli F. Hepatitis $\mathbf{C}$ virus and human immunodeficiency virus transmission routes: Differences and similarities. World J Hepatol 2013; 5:234-236.

6. Vickerman P, Hickman M, May M, Kretzschmar M, Wiessing L. Can hepatitis $C$ virus prevalence be used as a measure of injection-related human immunodeficiency virus risk in populations of injecting drug users? An ecological analysis. Addiction 2010; 105:311-318.

7. Vickerman $P$, Martin NK, Hickman M. Understanding the trends in HIV and hepatitis C prevalence amongst injecting drug users in different settings - implications for intervention impact. Drug Alcohol Depend 2012; 123:122-131.

8. Mathers BM, Degenhardt L, Phillips B, Wiessing L, Hickman M, Strathdee $S A$, et al. Global epidemiology of injecting drug use and HIV among people who inject drugs: a systematic review. Lancet 2008; 372:1733-1745.

9. Nelson PK, Mathers BM, Cowie B, Hagan H, Des Jarlais D, Horyniak D, et al. Global epidemiology of hepatitis B and hepatitis $C$ in people who inject drugs: results of systematic reviews. Lancet 2011; 378:571-583.

10. de Vos AS, van der Helm JJ, Prins M, Kretzschmar ME. Determinants of persistent spread of HIV in HCV-infected populations of injecting drug users. Epidemics 2012; 4:57-67.

11. Mirzoyan L, Berendes S, Jeffery C, Thomson J, Ben Othman H, Danon L, et al. New evidence on the HIV epidemic in Libya: why countries must implement prevention programs among people who inject drugs. J Acquir Immune Defic Syndr 2013; 62:577-583.

12. Borenstein M, Hedges LV, Higgins JPT, Rothstein HR. Introduction to meta-analysis. Chichester, UK: John Wiley \& Sons, Ltd.; 2009.

13. Nasir A, Todd CS, Stanekzai MR, Bautista CT, Botros BA, Scott PT, et al. Prevalence of HIV, hepatitis $B$ and hepatitis $C$ and associated risk behaviours amongst injecting drug users in three Afghan cities. Int J Drug Policy 2011; 22:145-152.

14. Todd CS, Abed AM, Strathdee SA, Scott PT, Botros BA, Safi N, et al. HIV, hepatitis C, and hepatitis B infections and associated risk behavior in injection drug users, Kabul, Afghanistan. Emerg Infect Dis 2007; 13:1327-1331.

15. Todd CS, Nasir A, Stanekzai MR, Fiekert K, Rasuli MZ, Vlahov $\mathrm{D}$, et al. Prevalence and correlates of HIV, syphilis, and hepatitis $B$ and $C$ infection and harm reduction program use among male injecting drug users in Kabul, Afghanistan: a crosssectional assessment. Harm Reduct / 2011; 8:22.

16. Afghanistan National AIDS Control Program. Integrated Behavioral \& Biological Surveillance (IBBS) in Afghanistan: Year 1 Report. HIV Surveillance Project - Johns Hopkins University School of Public Health, National AIDS Control Program, Ministry of Public Health. Kabul, Afghanistan; 2010.

17. Saleh E, El-Ghazzawi E, El-Sherbini I, Drew W, McFarland W Mandel J, et al. Sentinel surveillance for HIV and high risk behaviors among injection drug users in Alexandria, Egypt [Abstract no. 13124]. AIDS 1998 - XII International AIDS Conference; 28 June-3 July 1998, Geneva, Switzerland. 
18. Sarkari B, Eilami O, Khosravani A, Akbartabartori M, Tabatabaee $M$. High prevalence of hepatitis $C$ infection among high risk groups in Kohgiloyeh and Boyerahmad Province, Southwest of Iran. Int I Infect Dis 2011; 15:S82.

19. Kaffashian A, Nokhodian Z, Kassaian N, Babak A, Yaran M, Shoaei $P$, et al. The experience of hepatitis $C$ screening among prison inmates with drug injection history [Persian]. I Isfahan Med School 2011; 28:28.

20. Ataei B, Babak A, Yaran M, Kassaian N, Nokhodian Z, Meshkati $M$, et al. Hepatitis $C$ in intravenous drug users: seroprevalence and risk factors [Persian]. I Isfahan Med School 2011; 28:1-9.

21. Keramat F, Eini P, Majzoobi MM. Seroprevalence of HIV, HBV and $\mathrm{HCV}$ in persons referred to hamadan behavioral counseling center, west of Iran. Iran Red Cresc Med I 2011; 13:42-46.

22. Ghasemian R, Najafi N, Amirkhanloo K. The study of infections due to injection drug abuse in the injecting drug users hospitalized at Imam Khomeini Hospital in Sari and Razi Hospital in Ghaemshahr in 2007-2009. I Mazandaran Univ Med Sci 2011; 21:8-15.

23. Rahimi-Movaghar A, Razaghi EM, Sahimi-Izadian E, AminEsmaeili M. HIV, hepatitis C virus, and hepatitis B virus coinfections among injecting drug users in Tehran, Iran. Int J Infect Dis 2010; 14:e28-e33.

24. Merat S, Rezvan H, Nouraie M, Jafari E, Abolghasemi $H$, Radmard AR, et al. Seroprevalence of hepatitis C virus: the first population-based study from Iran. Int / Infect Dis 2010; 14(Suppl 3):e113-e116.

25. Kheirandish $P$, SeyedAlinaghi $S$, Jahani $M$, Shirzad $H$, Seyed Ahmadian M, Majidi A, et al. Prevalence and correlates of hepatitis $C$ infection among male injection drug users in detention, Tehran, Iran. J Urban Health 2009; 86:902-908.

26. Nobari RF, Meshkati M, Ataei B, Yazdani MR, Heidari K, Kassaian $\mathrm{N}$, et al. Identification of patients with hepatitis $\mathbf{c}$ virus infection in persons with background of intravenous drug use: the first community announcement based study from Iran. Int I Prevent Med 2012; 3:S170-S175.

27. Nokhodian Z, Meshkati M, Adibi P, Ataei B, Kassaian N, Yaran $M$, et al. Hepatitis $C$ among intravenous drug users in Isfahan, Iran: a study of seroprevalence and risk factors. Int J Prevent Med 2012; 3:S131-S138.

28. Kassaian N, Adibi P, Kafashaian A, Yaran M, Nokhodian Z, Shoaei $P$, et al. Hepatitis $C$ virus and associated risk factors among prison inmates with history of drug injection in Isfahan, Iran. Int J Prevent Med 2012; 3:S156-S161.

29. Alavi SM, Behdad F. Seroprevalence study of hepatitis $\mathbf{C}$ and hepatitis $B$ virus among hospitalized intravenous drug users in Ahvaz, Iran (2002-2006). Hepatitis Month 2010; 10:101-104.

30. Davoodian P, Dadvand H, Mahoori K, Amoozandeh A, Salavati A. Prevalence of selected sexually and blood-borne infections in injecting drug abuser inmates of bandar abbas and roodan correction facilities, Iran, 2002. Braz I Infect Dis 2009; 13:356358.

31. Sharif M, Sherif A, Sayyah M. Frequency of HBV, HCV and HIV infections among hospitalized injecting drug users in Kashan. Indian J Sex Transm Dis 2009; 30:28-30.

32. Alavi SM, Alavi L. Seroprevalence study of HCV among hospitalized intravenous drug users in Ahvaz, Iran (2001-2006). J Infect Public Health 2009; 2:47-51.

33. Vahdani P, Hosseini-Moghaddam SM, Family A, Moheb-Dezfouli R. Prevalence of HBV, HCV, HIV and syphilis among homeless subjects older than fifteen years in Tehran. Arch Iran Med 2009; 12:483-487.

34. Mirahmadizadeh AR, Majdzadeh R, Mohammad K, Forouzanfar $\mathrm{MH}$. Prevalence of HIV and hepatitis $C$ virus infections and related behavioral determinants among injecting drug users of drop-in centers in Iran. Iran Red Cresc Med I 2009; 11:325329.

35. Mir-Nasseri MM, Mohammadkhani A, Tavakkoli H, Ansari E, Poustchi $\mathrm{H}$. Incarceration is a major risk factor for blood-borne infection among intravenous drug users. Hepatitis Month 2011; 11:19-22.

36. Sayad B, Saeed FS, Keyvani H, Rezali M, Asadi T, Vaziri S, et al. Seroepidemiology of hepatitis C in Kermanshah (West of Iran, 2006). Hepatitis Month 2008; 8:141-146.

37. Zamani S, Ichikawa S, Nassirimanesh B, Vazirian M, Ichikawa $\mathrm{K}$, Gouya MM, et al. Prevalence and correlates of hepatitis $\mathbf{C}$ virus infection among injecting drug users in Tehran. Int I Drug Policy 2007; 18:359-363.
38. Pourahmad M, Javady A, Karimi I, Ataei B, Kassaeian N. Seroprevalence of and risk factors associated with hepatitis B, hepatitis C, and human immunodeficiency virus among prisoners in Iran. Infect Dis Clin Pract 2007; 15:368-372.

39. Sharifi-Mood B, Metanat M. Infection among hospitalized injection drug users. J Med Sci 2006; 6:686-689.

40. Amini S, Mahmoodabadi SA, Lamian S, Joulaie M, Farahani MM. Prevalence of hepatitis G virus (HGV) in high-risk groups and blood donors in Tehran, Iran. Iran I Public Health 2005; 34:41-46.

41. Alizadeh AH, Alavian SM, Jafari K, Yazdi N. Prevalence of hepatitis $\mathrm{C}$ virus infection and its related risk factors in drug abuser prisoners in Hamedan - Iran. World I Gastroenterol 2005; 11:4085-4089.

42. Rahbar AR, Rooholamini S, Khoshnood K. Prevalence of HIV infection and other blood-borne infections in incarcerated and nonincarcerated injection drug users (IDUs) in Mashhad, Iran. Int I Drug Policy 2004; 15:151-155.

43. Zali MR, Aghazadeh R, Nowroozi A, Amir-Rasouly H. AntiHCV antibody among Iranian IV drug users: is it a serious problem. Arch Iranian Med 2001; 4:115-119.

44. Mirahmadizadeh A, Kadivar M, Hemmati A, Javadi A. Infection with HIV and hepatitis $C$ and $B$ viruses among injecting drug users in Shiraz, Southern Iran [Abstract no. WePeC5981]. AIDS 2004 - XV International AIDS Conference; 11-16 July 2004, Bangkok, Thailand.

45. Aminzadeh Z. Seroepidemiology of HIV, syphilis, hepatitis B and $C$ in intravenous drug users at Loghman Hakim hospital]. Iran J Med Meicrobiol 2007; 1:53-56.

46. Mahfoud Z, Afifi R, Ramia S, El Khoury D, Kassak K, El Barbir F, et al. HIV/AIDS among female sex workers, injecting drug users and men who have sex with men in Lebanon: results of the first biobehavioral surveys. AIDS 2010; 24 Suppl 2:S45-S54.

47. Ramia S, Klayme S, Naman R. Infection with hepatitis B and C viruses and human retroviruses (HTLV-I and HIV) among highrisk Lebanese patients. Ann Trop Med Parasitol 2003; 97:187192.

48. Ahmed F, Irving WL, Anwar M, Myles P, Neal KR. Prevalence and risk factors for hepatitis $C$ virus infection in Kech District, Balochistan, Pakistan: most infections remain unexplained. A cross-sectional study. Epidemiol Infect 2012; 120:716-723.

49. Ali I, Siddique L, Rehman LU, Khan NU, Iqbal A, Munir I, et al. Prevalence of HCV among the high risk groups in Khyber Pakhtunkhwa. Virol / 2011; 8:296.

50. Ur Rehman L, Ullah I, Ali I, Khan IA, Iqbal A, Khan S, et al. Active hepatitis $\mathrm{C}$ infection and HCV genotypes prevalent among the IDUs of Khyber Pakhtunkhwa. Virol J 2011; 8:327.

51. Khanani MR, Ansari AS, Khan S, Somani M, Kazmi SU, Ali SH. Concentrated epidemics of HIV, HCV, and HBV among Afghan refugees. J Infect 2010; 61:434-437.

52. Platt L, Vickerman $P$, Collumbien M, Hasan S, Lalji N, Mayhew $\mathrm{S}$, et al. Prevalence of HIV, HCV and sexually transmitted infections among injecting drug users in Rawalpindi and Abbottabad, Pakistan: evidence for an emerging injectionrelated HIV epidemic. Sex Transm Infect 2009; 85 Suppl 2: ii17-II22.

53. Rehan N, Bokhari A, Nizamani NM, Jackson D, Naqvi HR, Qayyum K, et al. National study of reproductive tract infections among high risk groups of Lahore and Karachi. / Coll Physicians Surg Pak 2009; 19:228-231.

54. Abbasi S, Fagir F, Khan S, Zaidi SK, Ahmed SQ, Sattar A, et al. A serological study of hepatitis $C$ and human immunodeficiency virus in a cohort of intravenous drug users in Quetta, Baluchistan. I Postgrad Med Inst 2009; 23:3-6.

55. Altaf A, Shah SA, Zaidi NA, Memon A, Nadeem ur R, Wray N. High risk behaviors of injection drug users registered with harm reduction programme in Karachi, Pakistan. Harm Reduct J 2007; 4:7.

56. Achakzai M, Kassi M, Kasi PM. Seroprevalences and co-infections of HIV, hepatitis C virus and hepatitis B virus in injecting drug users in Quetta, Pakistan. Trop Doct 2007; 37:43-45.

57. Kuo I, ul-Hasan S, Galai N, Thomas DL, Zafar T, Ahmed MA, et al. High HCV seroprevalence and HIV drug use risk behaviors among injection drug users in Pakistan. Harm Reduct I 2006; 3:26.

58. UrRehman N. Injecting drug use and HIV/AIDS in Pakistan [Abstract no. MoPeD3667]. AIDS 2002 - XIV International AIDS Conference; 7-12 July 2002, Barcelona, Spain. 
59. Rahman K, Akhtar A, Aslam M. Seroprevalence of HIV, HBV \& $\mathrm{HCV}$ in drug users in Pakistan [Abstract no. CDC0097]. AIDS 2006 - XVI International AIDS Conference; 13-18 August 2006, Toronto, ON.

60. Hadi DHMH, Shujaat PDMGSH, Waheed PD.WuZ, Masood PDMGMA. Incidence of hepatitis $C$ virus and HIV among injecting drug users in Northern Pakistan: a prospective cohort study [Abstract no. MoOa0104]. IAS 2005 - The 3rd IAS Conference on HIV Pathogenesis and Treatment; 24-27 July 2005, Rio de Janeiro, Brazil.

61. Nai Zindagi, UNODCCP, UNAIDS. Baseline study of the relationship between injecting drug use, HIV and hepatitis $C$ among male injecting drug users in Lahore. Nai Zindagi, Punjab, Pakistan, 1999

62. Alzahrani AJ, Dela Cruz DM, Obeid OE, Bukhari HA, AlQahtani AA, Al-Ahdal MN. Molecular detection of hepatitis $B$, hepatitis C, and torque teno viruses in drug users in Saudi Arabia. I Med Virol 2009; 81:1343-1347.

63. Iqbal N. Substance dependence. A hospital based survey. Saudi Med / 2000; 21:51-57.

64. Njoh J, Zimmo S. Prevalence of antibodies to hepatitis $\mathbf{C}$ virus in drug-dependent patients in Jeddah, Saudi Arabia. East Afr Med / 1997; 74:89-91.

65. Othman BM, Monem FS. Prevalence of hepatitis $\mathbf{C}$ virus antibodies among intravenous drug abusers and prostitutes in Damascus, Syria. Saudi Med / 2002; 23:393-395.

66. Stulhofer A, Chetty A, Rabie RA, Jwehan I, Ramlawi A. The prevalence of HIV, HBV, HCV, and HIV-related risk-taking behaviors among Palestinian injecting drug users in the East Jerusalem Governorate. J Urban Health 2012; 89:671-676.

67. Khodadadizadeh A, Esmaeili Nadimi A, Hossieni SH, Shabani Sharbabaki Z. The prevalence of HIV, HBV and HCV in narcotic addicted persons referred to the out patient clinic of Rafsanjan university of medical sciences in 2003 [Persian]. ) Rafsanjan Univ Med Sci 2006; 5:21-30.

68. Altaf A, Shah SA. Follow up study to assess and evaluate knowledge, attitude and high risk behaviors and prevalence of HIV, HBV, HCV and Syphilis among IDUS at Burns Road DIC, Karachi. External report submitted to UNODC. Pakistan, 2003.

69. Tunisia Ministry of Health. Synthèse des enquêtes de séroprévalence et sérocomportementales auprès de trois populations à vulnérables au VIH: Les usagers de drogues injectables, les hommes ayant des rapports sexuels avec des hommes et les travailleuses du sexe clandestines en Tunisie [French, Synthesis of biobehavioral surveillance among the three populations vulnerable to HIV in Tunisia: injecting drug users, men who have sex with men, and female sex workers]. Tunis, Tunisia; 2010.

70. Morocco Ministry of Health, National AIDS Control Program, National Institute of Hygiene, UNAIDS, Global Fund to Fight AIDS Tuberculosis and Malaria. HIV integrated behavioral and biological surveillance surveys: Morocco 2011-2012: injecting drug users in Tanger and Nador, Morocco. Rabat, Morocco; 2012.

71. Tunisia Ministry of Health, Tunisian Association for Information and Orientation on HIV. Enquête sérocomportementale du VIH et des hépatites virales $C$ auprès des usagers de drogues injectables en Tunisie [French]. Biobehavioral surveillance of HIV and Hepatitis $\mathrm{C}$ among injecting drug users in Tunisia. Tunis, Tunisia; 2013

72. Alipour A, Haghdoost AA, Sajadi L, Zolala F. HIV prevalence and related risk behaviours among female partners of male injecting drugs users in Iran: results of a bio-behavioural survey, 2010. Sex Transm Infect 2013; 89 (Suppl 3):iii41iii44.

73. Alavian SM, Mirahmadizadeh A, Javanbakht M, Keshtkaran A, Heidari A, Mashayekhi A, et al. Effectiveness of methadone maintenance treatment in prevention of hepatitis $C$ virus transmission among injecting drug users. Hepat Mon 2013; 13:9.

74. Butt A, Jafri W, Janjua N, Pasha O. Seroprevalence and risk factors for hepatitis $\mathrm{C}$ infection among male prisoners in Karachi, Pakistan. Am J Gastroenterol 2010; 105:S112.

75. Nokhodian Z, Ataei B, Kassaian N, Yaran M, Hassannejad R, Adibi $P$. Seroprevalence and risk factors of hepatitis $C$ virus among juveniles in correctional center in Isfahan, Iran. Int J Prevent Med 2012; 3:S113-S117.
76. Eskandarieh S, Nikfarjam A, Tarjoman T, Nasehi A, Jafari F, Saberi-Zafarghandi MB. Descriptive aspects of injection drug users in Iran's National Harm Reduction Program by methadone maintenance treatment. Iran J Public Health 2013; 42:588-593.

77. Honarvar B, Odoomi N, Moghadami M, Afsar Kazerooni $P$, Hassanabadi A, Zare Dolatabadi P, et al. Blood-borne hepatitis in opiate users in Iran: a poor outlook and urgent need to change nationwide screening policy. PLOS One 2013; 8:e82230.

78. Afghanistan National AIDS Control Program. Integrated Behavioral \& Biological Surveillance (IBBS) in selected cities of Afghanistan: findings of 2012 IBBS survey and comparison to 2009 IBBS survey. Johns Hopkins University School of Public Health, National AIDS Control Program, Ministry of Public Health. Kabul, Afghanistan: Johns Hopkins University School of Public Health, National AIDS Control Program, Ministry of Public Health; 2012.

79. Pakistan National AIDS Control Program. HIV second generation surveillance in Pakistan. National Report Round IV. Canada-Pakistan HIV/AIDS Surveillance Project. National Aids Control Program, Ministry of Health, Pakistan. http://www.nacp. gov.pk/library/reports/Surveillance $\% 20 \& \% 20$ Research/HIV-AIDS $\% 20$ Surveillance $\% 20$ Project-HASP/HIV\%20Second\%20Generation $\% 20$ Surveillance $\% 20 \mathrm{in} \% 20$ Pakistan $\% 20-\% 20$ National\% 20report\%20Round\%20IV\%202011.pdf [Accessed 9 June 2015].

80. Pakistan National AIDS Control Program. HIV second generation surveillance in Pakistan. National Report Round III. CanadaPakistan HIV/AIDS Surveillance Project. National Aids Control Program, Ministry of Health, Pakistan. http://www.nacp.gov.pk/ library/reports/Surveillance\%20\&\%20Research/HIV-AIDS\%20 Surveillance $\% 20$ Project-HASP/HIV\%20Second\%20Generation $\%$ 20Surveillance $\% 20$ in $\% 20$ Pakistan $\% 20-\% 20$ National\%20report $\%$ 20Round\%20II\%202008.pdf [Accessed 9 June 2015].

81. Pakistan National AIDS Control Program. HIV second generation surveillance in Pakistan. National Report Round II. CanadaPakistan HIV/AIDS Surveillance Project. National Aids Control Program, Ministry of Health, Pakistan. http://www. nacp. gov.pk/ library/reports/Surveillance\%20\&\%20Research/HIV-AIDS\%20 Surveillance $\% 20$ Project-HASP/HIV\%20Second\%20Generation $\%$ 20Surveillance\%20in\%20Pakistan\%20-\%20Round\%202\%20 Report\%202006-07.pdf [Accessed 9 June 2015].

82. Pakistan National AIDS Control Program. HIV second generation surveillance in Pakistan. National Report Round I. CanadaPakistan HIV/AIDS Surveillance Project. National Aids Control Program, Ministry of Health, Pakistan. http://www.nacp.gov.pk/ library/reports/Surveillance $\% 20 \& \% 20$ Research/HIV-AIDS $\% 20$ Surveillance $\% 20$ Project-HASP/HIV\%20Second\%20Generation $\%$ 20Surveillance\%20in\%20Pakistan\%20-\%20Round\%201\%20 Report\%20-\%202005.pdf [Accessed 9 June 2015].

83. World Health Organization Regional Office for the Eastern Mediterranean. Antiretroviral therapy coverage. http://apps. who.int/gho/data/node.main.626?lang=en. [Accessed 9 June 2015].

84. Mohamoud YA, Miller FD, Abu-Raddad LJ. Potential for human immunodeficiency virus parenteral transmission in the Middle East and North Africa: an analysis using hepatitis $\mathrm{C}$ virus as a proxy biomarker. World I Gastroentero/ 2014; 20:12734-12752.

85. Abu-Raddad L, Akala FA, Semini I, Riedner G, Wilson D, Tawil O. Characterizing the HIV/AIDS epidemic in the Middle East and North Africa: time for strategic action. Middle East and North Africa HIV/AIDS Epidemiology Synthesis Project. World Bank/UNAIDS/WHO Publication. http://www-wds.worldbank.org/external/default/WDSContentServer/WDSP/IB/2010/06/ 04/000333038 20100604011533/Rendered/PDF/ 548890PUBOEPI11C10Dislosed061312010.pdf [Accessed 9 June 2015]. Washington, DC: The World Bank Press; 2010.

86. Abu-Raddad LJ, Schiffer JT, Ashley R, Mumtaz G, Alsallaq RA, Akala FA, et al. HSV-2 serology can be predictive of HIV epidemic potential and hidden sexual risk behavior in the Middle East and North Africa. Epidemics 2010; 2:173-182.

87. Incidence Assay Critical Path Working Group. More and better information to tackle HIV epidemics: towards improved HIV incidence assays. PLoS Med 2011; 8:e1001045.

88. Bao L, Ye J, Hallett TB. Incorporating incidence information within the UNAIDS Estimation and Projection Package framework: a study based on simulated incidence assay data. AIDS 2014; 28 (Suppl 4):S515-S522. 